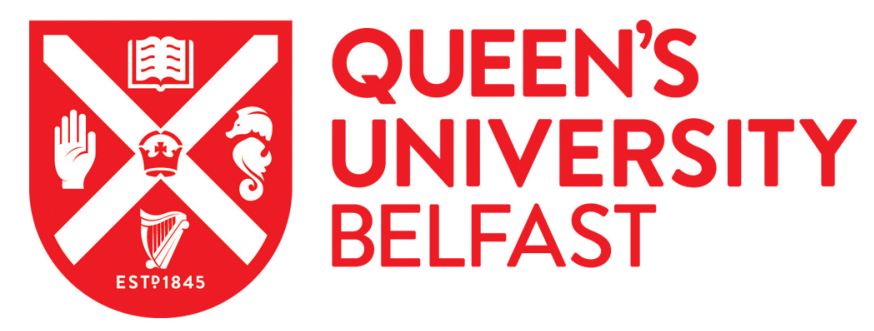

\title{
The Dark Triad, happiness and subjective well-being
}

Egan, VE., Chan, S., \& Shorter, G. W. (2014). The Dark Triad, happiness and subjective well-being. Personality and Individual Differences, 67, 17-22. https://doi.org/10.1016/j.paid.2014.01.004

\section{Published in:}

Personality and Individual Differences

\section{Document Version:}

Peer reviewed version

Queen's University Belfast - Research Portal:

Link to publication record in Queen's University Belfast Research Portal

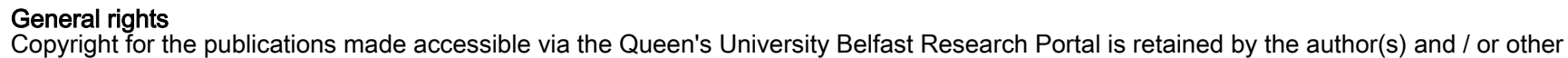
copyright owners and it is a condition of accessing these publications that users recognise and abide by the legal requirements associated with these rights.

Take down policy

The Research Portal is Queen's institutional repository that provides access to Queen's research output. Every effort has been made to ensure that content in the Research Portal does not infringe any person's rights, or applicable UK laws. If you discover content in the Research Portal that you believe breaches copyright or violates any law, please contact openaccess@qub.ac.uk. 


\section{The Dark Triad, happiness and subjective well-being}

Vincent Egan a*, Stephanie Chan b, Gillian W. Shorter c,d

a Centre for Family and Forensic Psychology, University of Nottingham, Yang Fujia Building, Jubilee Campus, Wollaton Road, Nottingham NG8 1BB, UK

b Home Team Behavioural Sciences Centre, Home Team Academy, Singapore 698928, Singapore c Bamford Centre for Mental Health and Wellbeing, University of Ulster, Londonderry, Northern Ireland d All Ireland Hub for Trials Methodology Research, University of Ulster, Londonderry, Northern Ireland

\section{Keywords}

Dark Triad, Happiness, Subjective well-being, Psychopathy, Narcissism, Machiavellianism, Five factor model, Latent profile analysis

Reference:

Egan, V., Chan, S., \& Shorter, G. W. (2014). The Dark Triad, happiness and subjective well-being. Personality And Individual Differences, 6717-22. doi:10.1016/j.paid.2014.01.004

* Corresponding author. Tel.: +44 1158466627.

E-mail address: vincent.egan@nottingham.ac.uk (V. Egan). 


\begin{abstract}
Narcissism can be expressed in grandiose or vulnerable forms. We examined whether positive psychological states (defined by the Oxford Happiness Inventory (OHI) and the Diener Satisfaction With Life (SWL) scales) assisted differentiation relative to general personality traits and the "the Dark Triad" (psychopathy, narcissism, and Machiavellianism, measured by the D12 and Short Dark Triad (SD3) indices) for 840 persons primarily from the UK, USA and Canada. The best fitting structural equation model comprised two latent variables, one of positive mood (comprising total scores on the $\mathrm{OHI}$ and SWL scales), and another forming a "dark dyad" of Machiavellianism and psychopathy (predicted by low agreeableness and lower positive mood), with narcissism regarded as a separate construct correlated with the dark dyad. Latent positive mood was primarily predicted by higher emotional stability and extraversion. Narcissism was predicted by lower emotional stability, lower agreeableness, and higher extraversion. Latent profile analysis identified four groups in the data: "unhappy but not narcissistic", "vulnerable narcissism", "happy non-narcissism" and "grandiose narcissism". Our results suggest more problematic narcissism can be identified by reference to measures indexing positive mood states and general personality traits.
\end{abstract}

Narcissism differentiates into grandiose and vulnerable forms (Pincus \& Lukowitski, 2010). Grandiose narcissists classically present as confident, self-centred, and other-oblivious, but can be wilful and exhibitionistic. Vulnerable narcissists are similar, but also hyper-sensitive and hostile. Vulnerable narcissists are inter-personally problematic, whereas grandiose narcissists can be highly effective leaders (Furnham, 2007). General non-antagonistic personality traits (for example, Agreeableness or low Neuroticism) and positive mood are moderating mechanisms that help differentiate narcissism (Gruber, Mauss, \& Tamir, 2011). The current study further tests this notion, examining the degree to which personality traits and positive emotions such as happiness and subjective well-being differentiate narcissism, relative to Machiavellianism and psychopathy (collectively known as the Dark Triad), and how these general personality traits underlie the Dark Triad as measured by a new omnibus test of the construct.

Meta-analyses using the Five Factor Model of personality (FFM; McCrae \& Costa, 1997) found Neuroticism (N) strongly predicts lower life satisfaction, less happiness, and more negative emotions, whereas Agreeableness (A) and Extraversion (E) predict positive emotions (DeNeve \& Cooper, 1998; Steel, Schmidt, \& Shultz, 2008). Antagonistic interpersonal behaviour is also predicted by personality; persons high in narcissism and Machiavellianism are more likely to disrupt the wellbeing of colleagues (Campbell, Hoffman, Campbell, \& Marchisio, 2011; Kessler et al., 2010); and narcissistic aggression is underpinned by low $A$ and $E$ (Egan \& Lewis, 2011). Vidal, Skeem, and Camp (2010) found persons in the community with higher secondary psychopathy (i.e., neurotic emotions concurrent with callous and grandiose traits) better at understanding subtle differences in the meanings of complex negative emotions (e.g., grief, depression, remorse, misery) than those with high primary psychopathy (characterised by callousness and fearless dominance). Similarly, Ali, Amorim, and Chamorro-Premuzic (2009) found persons with high primary psychopathy reported more positive emotions after viewing sad stimuli, whereas those with high secondary psychopathy experienced negative emotions even after viewing neutral stimuli. Del Gaizo and Falkenbach (2008) found persons with high primary psychopathy accurately recognised fearful facial expressions in others, experienced more positive emotions, and reported fewer negative emotions. Persons with greater secondary psychopathy were poor at recognising emotions in others, and experienced more negative emotions, perhaps because they were more absorbed in their own feelings. 
Emotions are often studied using negative constructs. However, positive emotional constructs such as subjective well-being (SWB; Diener, Suh, Lucas, \& Smith, 1999) and happiness - the state of having enjoyable feelings and making positive judgements (Ryan \& Deci, 2001) - are straightforward to measure, and help assess persons in a more rounded way. SWB and happiness are associated with greater physical and mental health, and with better relationships at work and in private lives (Argyle, 1987). The two constructs are not synonymous; while SWB is fundamental to happiness (Diener et al., 1999), happiness also involves social factors (Kashdan, 2004); for example, happiness is correlated with higher E (Argyle, Martin, \& Crossland, 1989).

Seeking to elaborate generic constructs associated with unpleasant dispositions, Paulhus and Williams (2002) examined the relationships between the Dark Triad and the FFM. They found that all components of the Dark Triad were negatively correlated with A; that narcissism correlated positively with $\mathrm{E}$ and Openness (O); that Machiavellianism and psychopathy correlated negatively with Conscientiousness (C); and that psychopathy was negatively correlated with $\mathrm{N}$ but positively correlated with E and O. Jakobwitz and Egan (2006) examined the Dark Triad, differentiating primary and secondary psychopathy. Their results confirmed the perennial correlation between the Dark Triad and A (Furnham, Richards, \& Paulhus, 2013). Principal components analysis of Jakobwitz et al's data revealed that secondary psychopathy was distinct, in that narcissism, Machiavellianism, and primary psychopathy were negatively correlated with $A$, whereas secondary psychopathy was also associated with high $\mathrm{N}$ and low C. Similar results followed when Ross, Lutz, and Bailley (2004) mapped primary and second ary psychopathy onto the FFM. Narcissism differs from more obviously "dark" personality traits as it has "brighter" elements, and can be attractive interpersonally (Rauthmann \& Kolar, 2012). We propose attractive aspects of potentially difficult personalities are identifiable using positive traits. This study predicts that general personality traits and positive mood differentiate narcissism more than they do Machiavellianism and psychopathy, which are largely driven by low $A$. We test this proposition using a large sample and recruit beyond student cohorts, using multivariate statistics to strongly test the hypothesis.

\section{Method and procedure}

\section{Participants}

The study opportunistically recruited 861 persons via Facebook and a variety of online Internetbased research sites. All included participants were fluent English speakers, and aged 18 years or over. To optimise integrity of information, we asked participants to respond to an attentional probe question with an "agree" response part way through the survey, and elsewhere to respond likewise with "disagree". This method identified 21 individuals who had not responded as requested, perhaps because they had not read the question correctly, responded randomly, or because they had a response set. When these 21 persons were excluded,the sample comprised 594 females and 246 males, mean participant age $=30.1$ years $(S D=12.7)$. The mean years of education for the cohort was $15.0(S D=3.8)$, although $216(25.7 \%)$ had 12 or fewer years of education, and so were unlikely to have a degree. Persons were recruited from the UK (375), the USA (306), Europe (70), Asia (42), Canada (30), Australasia (9), and Africa (8). Of the146 cohort, 441 (52.5\%) were currently in a relationship, while 399 (28.5\%) were single. As only 27 participants had prior criminal convictions, testing for forensic effects was unrealistic.

\section{Materials}


The International Personality Item Pool (IPIP), The IPIP (Goldberg, 1999) is a public domain measure of the Big Five personality dimensions; the version used in this study contained fifty statements (IPIP-50), requiring participants to indicate on a five-point scale how accurately each statement applied to their own personality. Responding ranges from 1 ("nothing like me") to 5 ("very much like me"). Ten statements corresponded to each personality trait with some statements being reversekeyed to avoid response set bias. Goldberg (1999) reports the mean reliability for each of the 5 scales to be 0.84 . Gow, Whiteman, Pattie, and Deary (2005) found the factor structure of the IPIP dimensions were very much equivalent to those assessed by the NEO-family of instruments, although the $\mathrm{N}$ dimension is inverted and called Emotional Stability (ES), and the $\mathrm{O}$ dimension is renamed Intellect (I). Egan and Taylor (2010) found the internal consistency reliabilities (Cronbach's alpha) for a UK sample satisfactory; $\mathrm{E}=0.84 ; \mathrm{A}=0.76 ; \mathrm{C}=0.77$, $\mathrm{ES}=0.87$, and $\mathrm{I}=0.73$.

The Short Dark Triad questionnaire (SD3). Jones and Paulhus (in press) describe a brief 27-item measure of Machiavellianism, psychopathy and narcissism, all of which have 9-item scales. Responding is made to a proposition on a 5-point scale ranging from 1 ("disagree strongly") to 5 ("agree strongly"). The factor structure was clear, and the scales reliable; Machiavellianism a = 0.75; psychopathy $\mathrm{a}=0.72 ;$ and narcissism $\mathrm{a}=0.73$ (Jones $175 \&$ Paulhus, in press).

The Dirty Dozen Scale (D12). The "dirty dozen" test (Jonason \& Webster, 2010) comprises 12 items to briefly measure the Dark Triad. Each item comprises a proposition which is rated on a 5-point scale from 1 ("strongly disagree") to 5 ("strongly agree"). Internal (test-retest) reliabilities for the two Machiavellian items are $a=0.79(0.89)$, six psychopathy items $a=0.77(0.74)$, and four narcissism items are $a=0.88(0.84)$.

Oxford Happiness Inventory (OHI). The OHI (Argyle et al., 1989) is a 29 -item scale used to measure happiness in non-clinical populations. Responses are scored on a 6-point scale, with responses ranging from 1 ("strongly disagree") to 6 ("strongly agree"). The scale has an overall internal reliability of 0.91 , with subscales being also reliable; mastery $(0.80)$, satisfaction $(0.81)$, social cheerfulness (0.74), vigour (0.67), and social interest (0.65) (Meleddu, Guicciardi, Scalas, \& Fadda, 2012).

The Satisfaction with Life Scale (SWLS). The SWLS (Diener, Emmons, Larsen, \& Griffin, 1985) is a brief (5-item), highly reliable $(a=0.87$, test-retest reliability $=0.82$ ) and well-validated measure of positive emotions. Persons respond to a proposition 195on a 7-point scale ranging from 1 ("strongly disagree") to 7 ("strongly agree"). In all cases, a higher scores on the measured construct indicated greater endorsement of the given trait.

\section{Procedure}

Participants were recruited online via a variety of social networking web sites, accruing responses via a variety of initiating Facebook pages, University bulletin boards, and the Hanover online Psychological research page. Participants were informed of the nature of the study and those who wished to take part consented online. Subjects then completed a brief series of questions describing their age, gender, education, nationality, marital status, and whether they had prior convictions. The full survey comprised 124 questions.

\section{Analysis}


All items were automatically written to file, allowing item-analyses for all scales. Scales were tested for internal reliability using Cronbach's alpha, and the two Dark Triad scales correlated as a means of providing convergent reliability. Measures were intercorrelated to examine the degree of shared variance between the different personality measures. Finally, structural equation models were calculated using AMOS (Arbuckle \& Wothke, 2003) using total scores for the measured variables for all participants. These examined how the latent variables of positive mood and the Dark Triad related to each other and to dark and normal personality traits for the SD3, as compared to the D12.

\section{Results}

Summary statistics for the scales used are presented in Table 1.All measures were reliable at $a=0.72$ or above except for OHI Social Cheerfulness $(a=0.63)$; results were comparable to published values. Exploratory correlations did not find age or education associated strongly with any personality construct; although by the nature of the large sample size, these small associations (typically0.1) were sporadically significant. Measured construct correlations between comparable indices on the SD3 and D12 were modest to acceptable (Machiavellianism $r=0.38, P<.001$; narcissism $r=0.50, P<$ .001 ; psychopathy $r=0.59, P<.001$ ). However, there was also considerable scale cross-correlation. These associations suggest that the some Dark Triad constructs and measures overlap considerably and are non-specific (Table 2).Structural equation models were fit to total scores, the models involving latent variables of positive mood (the $\mathrm{OHI}$ and SWLS total scores) and their relationship with general personality traits, in turn examining how these contributed to the Dark Triad. All measurement models comprised continuous scale summary scores for participants, rather than item-level indicators. The initial AMOS models tested if Machiavellianism, narcissism, and psychopathy loaded on a single Dark Triad latent variable. A far better fit was obtained by having a 'dark dyad' latent variable (psychopathy and Machiavellianism), with a separate, directly measured narcissism variable which was allowed to correlate with the dark dyad. Fit statistics for both SD3 and D12 models were acceptable, however, there were slight improvements in fit for a SD3-defined dark dyad (v2 (df) = 92.977 (22); GFI = 0.976; AGFI = 0.943; RMSEA = 0.064; CMIN/DF = 4.427), compared to dark dyad defined by the D12 (v2 (df) = 131.952 (22); GFI = 0.956; AGFI = 0.922; RMSEA = 0.077; CMIN/DF = 5.998). A combined model using both SD3 and D12 Dark Triad indices combined to increase the indicators for the relevant latent variables did not sharpen the fit of the model ( $\mathrm{V} 2$ (df) = 259.97; GFI = 0.948; AGFI = 0.905; RMSEA = 0.079; CMIN/DF = 6.190). The results of the structural equation model using the SD3 are presented in Fig. 1. We examined how personality traits related to latent positive mood and the dark dyad, and if positive mood related to these constructs. Latent positive mood was defined by the total score on the OHI and SWLS. Positive mood was associated primarily with $\mathrm{ES}$ and $\mathrm{E}$, with smaller (but significant) influences from the other IPIP dimensions. Though not associated with narcissism, latent positive mood was negatively associated with the latent 'dark dyad' ( 0.37 and 0.26 for the SD3 and D12, respectively). These results suggest that positive mood is the product of $E$ and ES, and is primarily associated with the more positive expression of narcissism, whereas the vulnerable elements of narcissism correlate with lower $A$, lower ES, and the dark dyad (itself negatively related to positive mood). The SD3-defined dark dyad is solely predicted by $A$ at 0.51 ( 0.66 for the D12). Our results suggest the SD3 narcissism measure can be interpreted as indicating grandiose or vulnerable narcissism if examined alongside general personality and positive mood traits. Finally, a latent profile analysis was conducted. A series of models with two to six profiles were run. A four profile model was selected the best fit of the data (Table 3). This was decided on the basis of the Lo-Mendel-Rubin Likelihood Ratio test (Lo, Mendel, 
\& Rubin, 2001). Though the information criteria did not conclusively suggest an optimal model, inspection of the profiles showed a four profile solution offered a theoretically sound profile relative to the more empirical three profile solution. The first profile represents a group with the least "happy" characteristics. This group were lowest on E, ES, I, the OHI total, and the SWLS, and comprised $21 \%$ of the sample. Vulnerable narcissists were similarly low on A but higher in selfreported I, highest in Machiavellianism, narcissism and psychopathy, and next most dissatisfied and unhappy relative to the unhappy non-narcissists: this group represented $23 \%$ of the cohort. The largest group were the grandiose narcissists, who comprised $31 \%$ of the sample. This group were the highest for $E, A, C$, and $E S$, and were equivalent to the vulnerable narcissists in higher self-rated intellect. They were highest on the $\mathrm{OHI}$ and SWL scales, and lower in psychopathy. The happy, nonnarcissistic group (25\% of the group) were also higher in A, and were less narcissistic, psychopathic, or Machiavellian (Fig. 2).

\section{Discussion}

We tested the degree to which positive emotions are associated with the Dark Triad, using general underlying personality traits to structure this information. While the two Dark Triad scales were correlated, they were also significantly correlated with their respective measures of Psychopathy and Machiavellianism. Structural equation models indicated better fit if one split the Dark Triad into a better-fitting dark dyad of Psychopathy and Machiavellianism, and a separate narcissism measure. Latent positive mood and dark dyad constructs were produced, with personality traits being fitted to these constructs. Both models were essentially the same, though the SD3's fitness indices were slightly better than those for the D12; combining both scales for indicators did not strengthen the fit of the model. Positive mood was particularly predicted by ES and E, whereas the dark dyad was predicted by low $A$, greater narcissism, and lower positive mood. Narcissism was particularly predicted by $E$, low $A$, and greater self-rated happiness. These findings reiterate narcissism's complexity and expression in relatively positive and negative forms (Ackerman et al., 2011). Latent profile analyses revealed four patterns of trait expression, supporting relationships shown in the SEM. These profiles reflected groups of persons who were unhappy, persons in the normal range (i.e., within 0.5 of a standard deviation of the mean for all measures), and grandiose and vulnerable narcissists. Grandiose narcissists were higher in E, ES, satisfaction with life, and general happiness; vulnerable narcissists were lower in A and ES, and higher in psychopathy and Machiavellianism.

Our results suggest differentiating grandiose and vulnerable narcissists may be relatively straightforward, answering the call Pincus and Lukowitski (2010) made regarding this need. In our data, vulnerable narcissists were not gregarious or socially interested, and were relatively anhedonic, even though they were not as markedly introverted, emotionally unstable or unhappy as our most troubled group. In future practice, informant ratings, sociometric evaluations of functioning within groups, and even, as here, self-report scales are all potentially applicable to making this behavioural differentiation. Our findings reaffirm in that happiness (which we extend by also including life satisfaction) is underpinned by ES and E (Robbins, Francis, \& Edwards, 2010).

We used two novel measures of the Dark Triad to examine which was more useful. Both scales were reliable, and internal and cross-test correlations were comparable. Our SEM models suggested the fit of personality and positive mood to the D12's Dark Triad measures was slightly poorer than that for the SD3. This may be because although the D12 is psychometrically rigorous in some respects (Webster \& Jonason, 2013), it focuses on the more callous-unemotional elements of psychopathy 
('primary psychopathy') than the interpersonally antagonistic and disinhibited aspects of the construct (Miller et al., 2012). Jonason and Luéano (2013) accept this critique, noting they seek to estimate complex traits using only a few items per dimension, leading to a loss of resolution. The D12 nevertheless remains useful in research where participant attention may be relatively transient, as in the case for studies involving offenders or the mentally disordered (e.g., Egan \& Beadman, 2011; Egan, Kavanagh, \& Blair, 2005).

Jonason and Luéano (op cit) also found the best-fitting model for their data was bifactorial: one dimension being psychopathy- Machiavellianism, the other narcissism. Our SEM analyses replicated this structure for the D12, and also for the SD3, underlying the separation of narcissism from the manipulative-callous dark core of what we called "the dark dyad" (Jones \& Figueredo, 2014; Rauthmann \& Kolar, 2012). Our data suggests that when scales of personality and positive mood are included, narcissism itself can be constructively differentiated, such that grandiose narcissism (or at least authentic pride in oneself) can be distinguished from often hubristic and destructive vulnerable narcissism.

Second-order personality constructs such as narcissism and psychopathy-Machiavellianism emerge out of lower-level personality traits with some emergent features of their own. These traits are adaptive when implemented in particular ecological niches; expressions of social dominance appear to enhance the effectiveness of mating effort (Egan \& Angus, 2004; Jonason, Li, \& Buss, 2010). Dark Triad traits maintain in the population because of the efforts persons high in the Dark Triad put into sexual activity, and because the traits they present may have been ancestral markers of biological fitness in a dangerous and unpredictable world rather different to most contemporary environments (Gangestad, Thornhill, \& Garver-Apgar, 2005). In this context, grandiose narcissism may have developed as a way to present social dominance, good-natured and confident pride being a way to compete with disagreeable persons primarily oriented to selfish and self-centred behavioural strategies (Dillon, Adair, Wang, \& Johnson, 2013). Positive states clarify and display this distinction and help observers evaluate threat from narcissistic peers.

Although our findings derive from good measures, a large and reasonably representative sample, and rigorous analysis, the study is not without faults. Central to these was that our measurement of narcissism was extremely brief, and did not actively test for differentiation of a priori scales of grandiose and vulnerable narcissism as indexed by the Narcissistic Personality Inventory (Ackerman et al., 2011) or the Pathological Narcissism Inventory (PNI; Pincus et al., 2009); some have suggested that the identification of prosocial aspects of narcissism is a consequence of using scales with items that more measure self-esteem than genuine narcissistic tendencies (Brown, Budzek, \& Tamborski, 2009; Veselka, Schermer, \& Vernon, 2012). While we accept this possibility, we sought to test the notion that general narcissism can be grandiose or vulnerable, depending on the configuration of traits it functions within, and our results upheld such a differentiation. It would nevertheless be helpful to replicate our findings with more extensive measures of narcissism and on occupational and clinical samples.

References

Ackerman, R. A., Witt, E. A., Donnellan, M. B., Trzesniewski, K. H., Robins, R. W., \& Kashy, D. A. (2011). What does the Narcissistic Personality Inventory Really Measure? Assessment, 18(1), 67-87. http://dx.doi.org/10.1177/ 1073191110382845. 
Ali, F., Amorim, I. S., \& Chamorro-Premuzic, T. (2009). Empathy deficits and trait emotional intelligence in Psychopathy and Machiavellianism. Personality and Individual Differences, 47(7), 758762. http://dx.doi.org/10.1016/i.paid.2009.06.016.

Arbuckle, J. L., \& Wothke, W. (2003). Amos 5.0 users guide. Chicago: SmallWaters. Argyle, M. (1987). The psychology of happiness. London, UK: Methuen.

Argyle, M., Martin, M., \& Crossland, J. (1989). Happiness as a function of personality and social encounters. In J. P. Forgas \& J. M. Innes (Eds.), Recent advances in social psychology: An international perspective (pp. 189-203). North-Holland: Elsevier.

Brown, R. P., Budzek, K., \& Tamborski, M. (2009). On the meaning and measure of narcissism. Personality and Social Psychology Bulletin, 35(7), 951-964. http:// dx.doi.org/10.1177/0146167209335461.

Campbell, W. K., Hoffman, B. J., Campbell, S. M., \& Marchisio, G. (2011). Narcissism in organizational contexts. Human Resource Management Review, 21(4), 268-284.

http://dx.doi.org/10.1016/i.hrmr.2010.10.007.

Del Gaizo, A., \& Falkenbach, D. (2008). Primary and secondary psychopathic-traits and their relationship to perception and experience of emotion. Personality and Individual Differences, 45(3), 206-212. http://dx.doi.org/10.1016/j.paid. 2008.03.019.

DeNeve, K. M., \& Cooper, H. (1998). The happy personality: A meta-analysis of 137 personality traits and subjective well-being. Psychological Bulletin, 124(2), 197-229. http://dx.doi.org/10.1037/00332909.124.2.197.

Diener, E., Emmons, R. A., Larsen, R. J., \& Griffin, S. (1985). The satisfaction with life scale. Journal of Personality Assessment, 49(1), 71-75. http://dx.doi.org/10.1207/ s15327752jpa4901_13.

Diener, E., Suh, E. M., Lucas, R. E., \& Smith, H. L. (1999). Subjective well-being: Three decades of progress. Psychological Bulletin, 125(2), 276-302. http://dx.doi.org/ 10.1037/0033-2909.125.2.276.

Dillon, H. M., Adair, L. E., Wang, Z., \& Johnson, Z. (2013). Slow and steady wins the race: Life history, mate value, and mate settling. Personality and Individual Differences, 55(5), 612-618.

http://dx.doi.org/10.1016/i.paid.2013.05.015.

Egan, V., \& Angus, S. (2004). Is social dominance a sex-specific strategy for infidelity? Personality and Individual Differences, 36(3), 575-586. http:// dx.doi.org/10.1016/S0191-8869(03)00116-8.

Egan, V., \& Beadman, M. (2011). Personality and gang embeddedness. Personality and Individual Differences, 51(6), 748-753. http://dx.doi.org/10.1016/j.paid. 2011.06.021.

Egan, V., Kavanagh, B., \& Blair, M. (2005). Sexual offenders, personality and obsessionality. Sexual Abuse, 17(3), 223-240. http://dx.doi.org/10.1177/ 107906320501700301.

Egan, V., \& Lewis, M. (2011). Neuroticism and agreeableness differentiate emotional and narcissistic expressions of aggression. Personality and Individual Differences, 50(6), 845-850.

http://dx.doi.org/10.1016/j.paid.2011.01.007. 
Egan, V., \& Taylor, D. (2010). Shoplifting, unethical consumer behaviour, and personality. Personality and Individual Differences, 48(8), 878-883. http:// dx.doi.org/10.1016/j.paid.2010.02.014.

Furnham, A. (2007). Personality disorders and derailment at work: The paradoxical positive influence of pathology in the workplace. In J. Langan-Fox, C. L. Cooper, \& R. J. Klimoski (Eds.), Research companion to the dysfunctional workplace (pp. 22-39). Cheltenham: Edward Elgar.

Furnham, A., Richards, S. C., \& Paulhus, D. L. (2013). The Dark Triad of personality: A 10 year review. Social and Personality Psychology Compass, 7(3), 199-216. http:// dx.doi.org/10.1111/spc3.12018.

Gangestad, S. W., Thornhill, R., \& Garver-Apgar, C. E. (2005). Women's sexual interests across the ovulatory cycle depend on primary partner developmental instability. Proceedings of the Royal Society B: Biological Sciences, 272(1576), 2023-2027. http://dx.doi.org/10.1098/rspb.2005.3112.

Goldberg, L. R. (1999). A broad-bandwidth, public-domain, personality inventory measuring the lower-level facets of several five-factor models. In I. Mervielde, I. Deary, F. De Fruyt, \& F. Ostendorf (Eds.). Personality psychology in Europe (Vol. 7, pp. 7-28). Tilburg, The Netherlands: Tilburg University Press.

Gow, A. J., Whiteman, M. C., Pattie, A., \& Deary, I. J. (2005). Goldberg's 'IPIP' Big-Five Factor markers: Internal consistency and concurrent validation in Scotland. Personality and Individual Differences, 39(2), 317-329. http://dx.doi.org/10.1016/ j.paid.2005.01.011.

Gruber, J., Mauss, I. B., \& Tamir, M. (2011). A dark side of happiness? How, when, and why happiness is not always good. Perspectives on Psychological Science, 6, 222-233. http://dx.doi.org/10.1177/1745691611406927.

Jakobwitz, S., \& Egan, V. (2006). The 'Dark Triad' and normal personality traits. Personality and Individual Differences, 40(2), 331-339. http://dx.doi.org/10.1016/ j.paid.2005.07.006.

Jonason, P. K., Li, N. P., \& Buss, D. M. (2010). The costs and benefits of the Dark Triad: Implications for mate poaching and mate retention tactics. Personality and Individual Differences, 48(4), 373378. http://dx.doi.org/10.1016/j.paid.2009. 11.003.

Jonason, P. K., \& Luéano, V. X. (2013). Walking the thin line between efficiency and accuracy: Validity and structural properties of the Dirty Dozen. Personality and Individual Differences, 55(1), 76-81. http://dx.doi.org/10.1016/j.paid.2013.

02.010. Jonason, P. K., \& Webster, G. D. (2010). The dirty dozen: A concise measure of the Dark Triad. Psychological Assessment, 22(2), 420-432. http://dx.doi.org/10.1037/ a0019265.

Jones, D.N., \& Paulhus, D.L. (2013). Introducing the Short Dark Triad (SD3): A brief measure of dark personality traits. Assessment, accepted for publication.

Jones, D. N., \& Figueredo, A. J. (2014). The core of darkness: Uncovering the heart of the Dark Triad. European Journal of Personality, 27(6), 521-531. http:// dx.doi.org/10.1002/per.1893. 
Kashdan, T. B. (2004). The assessment of subjective well-being (issues raised by the Oxford Happiness Questionnaire). Personality and Individual Differences, 36(5), 1225-1232.

http://dx.doi.org/10.1016/S0191-8869(03)00213-7.

Kessler, S. R., Bandelli, A. C., Spector, P. E., Borman, W. C., Nelson, C. E., \& Penney, L. M. (2010). Reexamining Machiavelli: A three-dimensional model of Machiavellianism in the workplace. Journal of Applied Social Psychology, 40(8), 1868-1896. http://dx.doi.org/10.1111/j.1559-1816.2010.00643.x.

Lo, Y., Mendel, N. R., \& Rubin, D. B. (2001). Testing the number of components in a normal mixture. Biometrika, 88(3), 767-778. http://dx.doi.org/10.1093/biomet/ 88.3.767.

McCrae, R. R., \& Costa, P. T. Jr, (1997). Personality trait structure as a human universal. American Psychologist, 52(5), 509-516. http://dx.doi.org/10.1037/ 0003-066X.52.5.509.

Meleddu, M., Guicciardi, M., Scalas, L. F., \& Fadda, D. (2012). Validation of an Italian version of the Oxford Happiness Inventory in adolescence. Journal of Personality Assessment, 94(2), 175-185. http://dx.doi.org/10(1080/00223891), 2011, 645931.

Miller, J. D., Few, L. R., Seibert, L. A., Watts, A., Zeichner, A., \& Lynam, D. R. (2012). An examination of the Dirty Dozen measure of Psychopathy: A cautionary tale about the costs of brief measures. Psychological Assessment, 24(4), 1048-1053. http://dx.doi.org/10.1037/a0028583.

Paulhus, D. L., \& Williams, K. M. (2002). The Dark Triad of personality: Narcissism, Machiavellianism and Psychopathy. Journal of Research in Personality, 36(6), 556-563.

http://dx.doi.org/10.1016/S0092-6566(02)00505-6.

Pincus, A. L., Ansell, E. B., Pimentel, C. A., Cain, N. M., Wright, A. G., \& Levy, K. N. (2009). Initial construction and validation of the Pathological Narcissism Inventory. Psychological Assessment, 21(3), 365-379. http://dx.doi.org/10.1037/a0016530.

Pincus, A. L., \& Lukowitski, M. R. (2010). Pathological Narcissism and narcissistic personality disorder. Annual Review of Clinical Psychology, 6, 421-446.

http://dx.doi.org/10.1146/annurev.clinpsy.121208.131215.

Rauthmann, J. F., \& Kolar, G. P. (2012). How "dark" are the Dark Triad traits? Examining the perceived darkness of Narcissism, Machiavellianism, and Psychopathy. Personality and Individual Differences, 53(7), 884-889. http:// dx.doi.org/10.1016/j.paid.2012.06.020.

Robbins, M., Francis, L. J., \& Edwards, B. (2010). Happiness as stable extraversion: Internal consistency reliability and construct validity of the Oxford Happiness Questionnaire among undergraduate students. Current Psychology, 29(2), 89-94. http://dx.doi.org/10.1007/s12144-0109076-8.

Ross, S. R., Lutz, C. J., \& Bailley, S. E. (2004). Psychopathy and the Five Factor Model in a noninstitutionalized sample: A domain and facet level analysis. Journal of Psychopathology and Behavioral Assessment, 26(4), 213-223. http://dx.doi.org/ 10.1023/B:JOBA.0000045337.48535.a5. 
Ryan, R. M., \& Deci, E. L. (2001). On happiness and human potentials: A review of research on hedonic and eudaimonic well-being. Annual Review of Psychology, 52(1), 141-166.

http://dx.doi.org/10.1146/annurev.psych.52.1.141.

Steel, P., Schmidt, J., \& Shultz, J. (2008). Refining the relationship between personality and subjective well-being. Psychological Bulletin, 134(1), 138-161. http://dx.doi.org/10.1037/0033-2909.134.1.138.

Veselka, L., Schermer, J. A., \& Vernon, P. A. (2012). The Dark Triad and an expanded framework of personality. Personality and Individual Differences, 53(4), 417-425.

http://dx.doi.org/10.1016/j.paid.2012.01.002.

Vidal, S., Skeem, J., \& Camp, J. (2010). Emotional intelligence: Painting different paths for lowanxious and high-anxious psychopathic variants. Law and Human Behavior, 34(2), 150-163. http://dx.doi.org/10.1007/s10979-009-9175-y.

Webster, G. D., \& Jonason, P. K. (2013). Putting the "IRT" in "Dirty": Item response theory analyses of the Dark Triad Dirty Dozen - An efficient measure of Narcissism, Psychopathy, and Machiavellianism. Personality and Individual Differences, 54(2), 302-306.

http://dx.doi.org/10.1016/i.paid.2012.08.027 
Table 1: means, standard deviations and reliability of measurements.

Measure

$\underline{\text { IPIP }}$

Emotional stability

Extroversion

Intellect

Agreeableness

Conscientiousness

$\underline{\mathrm{SD} 3}$

Machiavellianism

Narcissism

Psychopathy

DT12

Machiavellianism

Narcissism

Psychopathy

Positive mood

Oxford Happiness Inventory $(\mathrm{OHI})$ total $\quad 91.4 \quad 17.2 \quad 0.92$

$\mathrm{OHI}$ Mastery

OHI Satisfaction

OHI Vigour

OHI Social Interest

OHI Social Cheerfulness

Diener Satisfaction With Life Scale
Mean SD Alpha reliability

$\begin{array}{lll}28.0 & 7.9 & 0.88\end{array}$

$\begin{array}{lll}30.0 & 7.7 & 0.88\end{array}$

$\begin{array}{lll}37.4 & 5.9 & 0.80\end{array}$

$\begin{array}{lll}38.5 & 6.0 & 0.85\end{array}$

$\begin{array}{lll}33.6 & 6.1 & 0.78\end{array}$

$\begin{array}{lll}2.83 & 0.58 & 0.74\end{array}$

$\begin{array}{lll}2.70 & 0.63 & 0.74\end{array}$

$\begin{array}{lll}2.07 & 0.62 & 0.76\end{array}$

$\begin{array}{lll}3.2 & 1.6 & 0.72\end{array}$

$\begin{array}{lll}11.2 & 3.1 & 0.73\end{array}$

$\begin{array}{lll}14.5 & 4.5 & 0.74\end{array}$

$\begin{array}{lll}31.1 & 6.9 & 0.82\end{array}$

$\begin{array}{lll}20.2 & 4.9 & 0.86\end{array}$

$\begin{array}{lll}14.9 & 3.9 & 0.72\end{array}$

$\begin{array}{lll}6.93 & 1.7 & 0.63\end{array}$

$\begin{array}{lll}18.3 & 3.5 & 0.77\end{array}$

$\begin{array}{lll}14.6 & 4.5 & 0.86\end{array}$ 
Table 2: Correlations (Pearson's r) between SD3 and DT12 measures of the dark triad ( $n=840)$.

SD3

DT12

Machiavellianism Narcissism Psychopathy

$\begin{array}{lccc}\text { Machiavellianism } & \underline{0.38} & 0.27 & 0.55 \\ \text { Narcissism } & 0.21 & \underline{0.50} & 0.24 \\ \text { Psychopathy } & 0.51 & 0.29 & \underline{0.59}\end{array}$

Table legend: All coefficients one-tailed and significant at P<.001; DT12 is the short form 12 -item measure of the dark triad; SD3 the 28-item measure of the same construct. Underlined coefficients show the agreement for key constructs between test instruments. 
Table 3: Loadings of pattern matrix from factor analysis of study measures using oblique rotation ( $n=840 ; 20$ iterations).

$\begin{array}{lll}\text { F1 } & F 2 & F 3\end{array}$

\begin{tabular}{|c|c|c|c|}
\hline OHI Mastery & $\underline{0.86}$ & 0.03 & 0.15 \\
\hline OHI Vigour & $\underline{0.81}$ & 0.14 & 0.09 \\
\hline Emotional Stability & $\underline{0.80}$ & -0.02 & -0.12 \\
\hline OHI Life Satisfaction & $\underline{0.74}$ & -0.16 & 0.27 \\
\hline Total SWB & $\underline{0.72}$ & -0.09 & 0.15 \\
\hline Conscientiousness & $\underline{0.54}$ & 0.00 & -0.21 \\
\hline SD3 psychopathy & -0.10 & $\underline{0.75}$ & 0.23 \\
\hline Agreeableness & -0.08 & $\underline{-0.75}$ & $\underline{0.47}$ \\
\hline SD3 Machiavellianism & -0.10 & $\underline{0.73}$ & 0.03 \\
\hline D12 Machiavellianism & 0.19 & $\underline{0.72}$ & -0.10 \\
\hline D12 Psychopathy & -0.23 & $\underline{0.70}$ & 0.21 \\
\hline OHI Social Interest & 0.14 & $\underline{-0.53}$ & $\underline{0.52}$ \\
\hline Extroversion & 0.33 & -0.04 & $\underline{0.65}$ \\
\hline SD3 Narcissism & 0.23 & $\underline{0.46}$ & $\underline{0.60}$ \\
\hline $\mathrm{OHI}$ Cheerfulness & $\underline{0.45}$ & -0.16 & $\underline{0.54}$ \\
\hline Intellect & -0.05 & 0.00 & $\underline{0.50}$ \\
\hline D12 Narcissism & -0.06 & $\underline{0.43}$ & $\underline{0.50}$ \\
\hline Rotated eigenvalue & 4.47 & 3.59 & 2.81 \\
\hline$\%$ variance & 30.7 & 18.7 & 9.5 \\
\hline
\end{tabular}

Table legend: loadings over 0.40 underlined and in bold; $r F 1 / F 2=-0.16, P<.001 ; r$ F1/F3 $=0.20$, $P<.001 ; r F 2 / F 3=0.03$ (n.s.) 
Table 4: Fit statistics of latent class analysis for ten personality indicators.

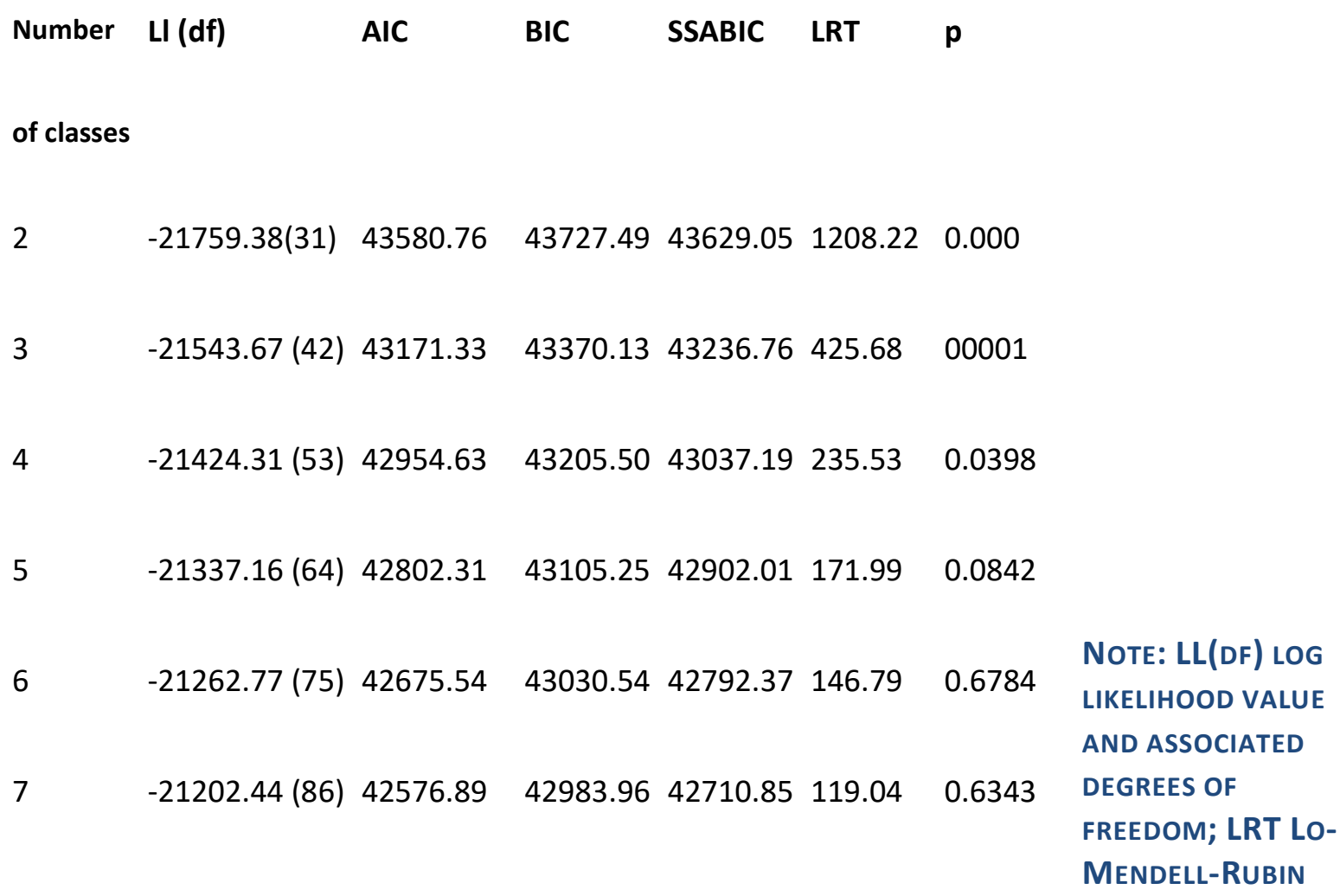

Adjusted likelihood ratio test value; AiC Akaike Information Criterion; BiC Bayesian Information Criterion; SSABIC Sample Size Adjusted Bayesian Information Criterion 
Figure 1: SEM of subjective positive mood, the dark triad (SD3) and measured personality traits (IPIP).

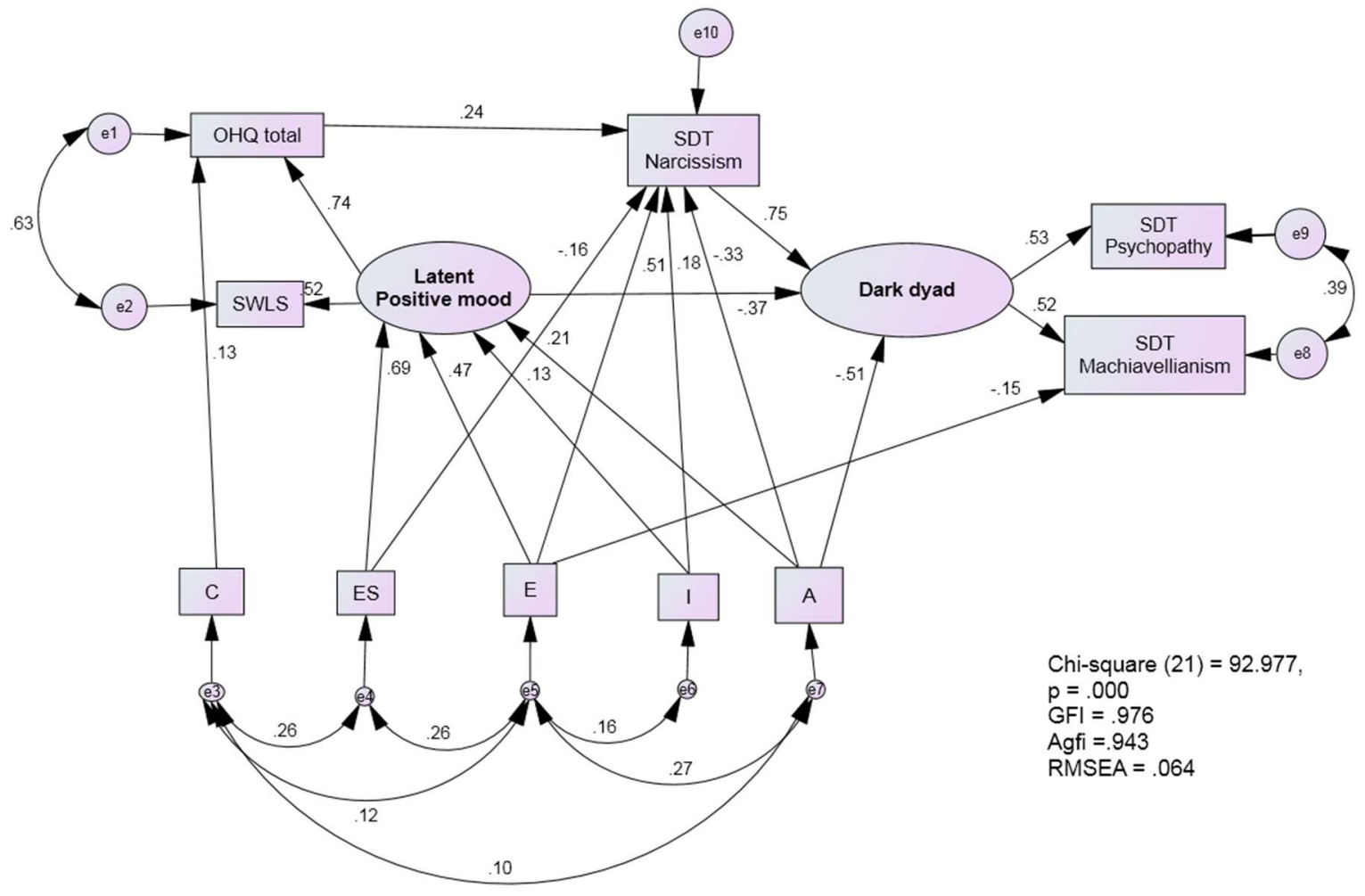

Table legend: Narcissism contributes substantially to a latent "dark dyad", but functions independently of the latent variable, being predicted by a broad variety of other measured variables. The dark dyad, however, is predicted primarily by lower positive mood and lower agreeableness. 
Figure 2: Standardised ( $z$-score) means for the four personality latent profiles $(n=840)$.

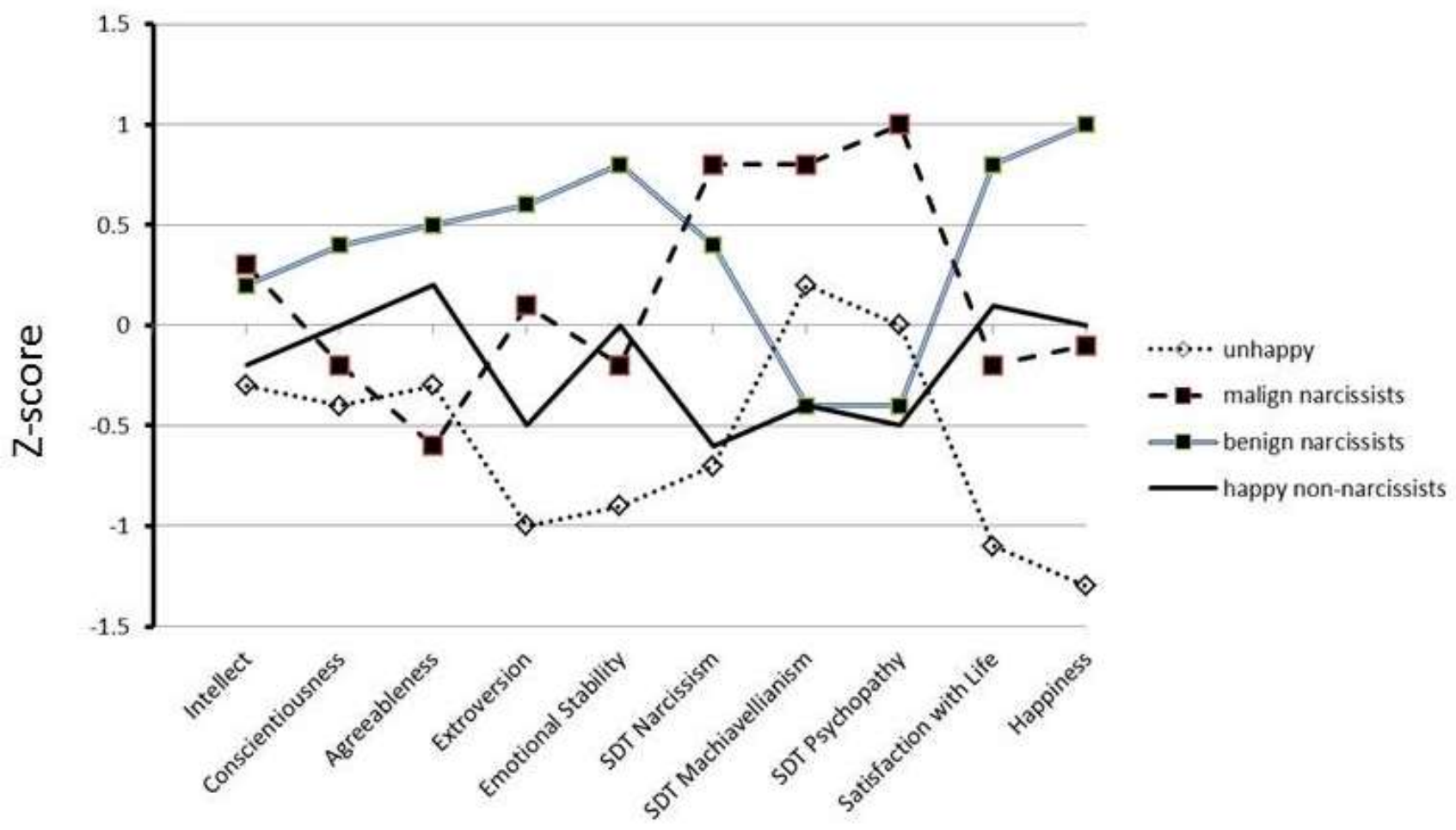

